\title{
Substantiation of the parameters constructions platform with electric drive for harvesting strawberries
}

\author{
Rostislav Filippov ${ }^{1, *}$, Dmitriy Khort $^{1}$, and Igor Smirnov ${ }^{1}$ \\ ${ }^{1}$ Federal Scientific Agroengineering Center VIM, 1-st Institutsky proezd, 5, Moscow, 109428, Russia.
}

\begin{abstract}
The article presents an analysis of possible options for placing the berry picker using various technical means, the calculation of energy costs on the slopes during operation, as a result of which it is established that for a more efficient process of harvesting strawberries with the least degree of fatigue, the pickers should be located on the site located between two adjacent rows. The results of computer modeling and laboratory and bench modeling were presented, the area mastered by the picker during the work was found, the parameters of the workplace picker were justified. As a result of the research, an original design of a self-propelled platform with an electric drive with adjustable technical parameters was proposed and developed.
\end{abstract}

\section{Introduction}

It is known that to obtain high yields of fruit and berry crops, an important factor is the high level of mechanization of the main production processes in industrial horticulture. Until now, even in large horticultural farms manual labor remains dominant, which in turn constrains the rate of production and the volume of fruits and berries grown.

Among berry crops the least mechanized (7.4\%) cultivation of strawberries. Production pome fruit crops mechanized $20.5 \%$, and stone $-13.0 \%[1,2]$. One of the factors hindering the development of its own industrial production of berry crops in the country is the dominance of manual labor in harvesting operations, including such a culture as strawberries. Hands method of harvesting strawberries is to separate a work ripe berries, put them in a container and subsequent accumulation, but long-term hand picking berries on industrial plantations leads within the working day to an invalid physical overload of the body and is aggravated by the need at the same time picking berries are constantly moved around the plantation empty and fill the berry containers.

Therefore, a special role is played by those means of mechanization, the use of which not only significantly reduces labor costs, but also allow it to be greatly facilitated when performing manual operations. In particular, such means include trolleys and platforms as a driving force in which, among other things, electric motors with reducers, electric motor

\footnotetext{
${ }^{*}$ Corresponding author: rostislav-filippov@yandex.ru
} 
wheels with partial recharging from solar batteries or from a portable gasoline generator can be used. [3]. Therefore, the work on the justification of self-propelled electric platforms that can be used not only for harvesting strawberry garden but also on other technological operations, such as planting weeding and others, is an urgent task.

When designing a platform, it is important to combine several important parameters in the design process:

- optimal position of the operator during operation;

- high performance platform while moving on the soil fertility with varying degrees of soil moisture;

- ensure sufficient battery life for the entire shift;

- ensuring the work platform on the planting low-growing crops with different aisles.

\section{Materials and methods}

The paper uses generally accepted methods of mathematical processing experimental data. Elements of system analysis were used for complex solution tasks. Theoretical studies were carried out on the basis of known provisions higher mathematics and physics. Experimental laboratory studies were carried out according to conventional research methods using the method of questioning, organoleptic method. Modeling technological processes and processing of the main results experiments was carried out using software CAD Compass3D v17, Autodesk fusion 360, MathCad 15.

When calculating the parameters of the workplace collector in a sitting position on the basis of anthropometric data, take into account the selected coordinate system and the corresponding reference base, the working position worker; the possibility of changing the position body, the magnitude working movements, the number of elements workplace, the visibility parameters, the ability to adjust the parameters elements workplace; the possibility of mobility elements workplace (seat, footrest, levers), data for calculations, taking into account the sizes of the figures collectors have enjoyed GOST 17521-72 "Standard figures of men to design clothes", GOST 17522-72 "Typical figures of women, dimensional characteristics for designing clothes".

And then finally determined the structural features and dimensions of the platform.

The convenience of the workplace depends on many components, the ability to adjust the height seat, the distance to the footrests, the height of the pedals. To clarify the optimal parameters application seat for the platform provides a possible range of adjustments. The organoleptic method was adopted together with the method of expert assessments. The expert method is based on the views of a group of professional experts, which may include different categories of citizens. These methods were used in the laboratory to clarify some parameters of the workplace, as well as to study the size range motor field hands. Expert group consisted of 10 people.

To find the area picking of strawberries used computer modeling in Avtodesk fusion 360 CAD software Kompas-3D v17. As well as laboratory bench-scale testing.

\section{Results and discussions}

After reviewing the use various technical means for hand harvesting of strawberries, it can be stated that the pickers can take four types of positions :

- lying over a row strawberries face down and support the forehead or chin on one stand or without support;

- reclining over a row of strawberries face down and supporting the body on three supports, (chest and both knees); 
- sitting between two rows of strawberries with feet resting on the ground or stand; - sitting on a number of strawberries with support legs on the stand.

The picking berries one picker from two rows with a discrete movement of the platform is more stable, and its share in the total harvesting cycle increases to $80 \%$. At the same time, the total movement of the self-moving platform is at least two times less than the tractor unit with a multi-seat platform, and soil compaction practically does not occur.

The convenient pose of the worker allows with the minimum expenses of energy (in comparison with traditional manual collecting in the bent position) to conduct productive cleaning of berries with high quality [4].

Therefore, we define the energy cost picker of berries on committed work was at the same position (Fig. 1).

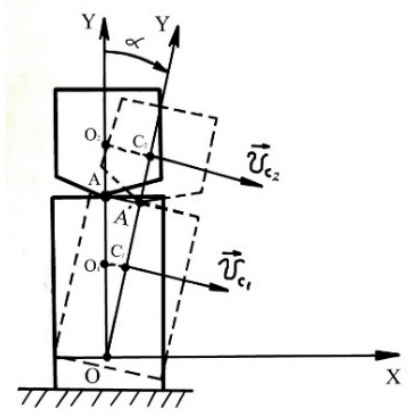

Fig. 1. Diagram of the front deviation of the collector while working in a sitting position.

To do this, we use a dynamic (biomechanical) model human body (head and body, ie, upper and lower mass), performing slopes when picker berries, and we believe that the head (upper mass) does not make rotational movements relative to point A (Atlas-occipital joint). when collecting strawberries, the worker has to perform minor slopes, both the head and body in the frontal plane (other turns with a rotating seat are practically absent, so they can not be taken into account).

This means that in determining the energy costs for the specified position of the berry picker, it is possible to limit the conditional oscillations of the upper and lower masses only in the above-mentioned plane.

The total kinetic energy T consists of the kinetic energy of the upper T2 (head) and lower T1 (body) of the person:

$$
\begin{gathered}
T=T_{1}+T_{2} \\
T_{1}=\frac{m_{1} V_{c 1}^{2}}{2} \text { и } T_{2}=\frac{m_{2} V_{\mathrm{c} 2}^{2}}{2}
\end{gathered}
$$

where $\mathrm{m}_{1}$ - weight of the middle part body, $\mathrm{m}_{2}$ - linear velocities of the mass centers body and head picker, $V c_{1}, u V c_{2}$ - linear velocities of the mass centers body and head picker.

These speeds are determined by the formulas:

$$
V_{c 1}=\omega_{1} O C_{1}=\dot{\alpha_{1}} O C_{1} ; V_{c 2}=\omega_{2} O C_{2}=\dot{\alpha_{2}} O C_{2},
$$

Here - $\mathrm{OC}_{1}$ и $\mathrm{OC}_{2}$ - the distance of the centers mass $\mathrm{C}_{1}$ and $\mathrm{C}_{2}$ from point $\mathrm{O}$, head).

$\omega_{1}=\alpha_{1}=\dot{\alpha}$ and $\omega_{2}=\alpha_{2}=\dot{\alpha}$ - angular velocities of lower and upper masses (body and

At the maximum angle of inclination in $30^{\circ}$ values $\omega_{l}$ and $\omega_{2}$ will be the same and equal

$$
\omega_{1}=\omega_{2}=\dot{a}\left(\frac{\pi}{6} t\right)_{t}^{\prime}=\frac{\pi}{6}
$$


Distances $\mathrm{OC}_{1}$ and $\mathrm{OC}_{2}$ take equal $\mathrm{OC}_{1}=0,3 \mathrm{~m}, \mathrm{OC}_{2}=0,6 \mathrm{~m}$ substituting in expressions, get:

or

$$
\begin{gathered}
T=\frac{m_{1} V_{c 1}^{2}}{2}+\frac{m_{2} V_{\mathrm{c} 2}^{2}}{2}-\frac{1}{2}\left[m_{1}\left(\dot{\alpha} \mathrm{OC}_{1}\right)^{2}+m_{1}\left(\dot{\alpha} \mathrm{OC}_{2}\right)^{2}\right] \\
T=\frac{1}{2} \dot{\alpha}\left(m_{1} O C_{1}^{2}+m_{2} O C_{2}^{2}\right)
\end{gathered}
$$

Take $\mathrm{m}_{1}=25,5 \mathrm{~kg}$ and $\mathrm{m}_{2}=5 \mathrm{~kg}$. Then, for one slope, the picker will spend energy equal to

$$
T=\frac{1}{2}(25,5 \cdot 0,09+5 \cdot 0,39)=1,07
$$

On average, a shift of the picker commits 854 tilt. Therefore, the energy consumption per shift, only on slopes, will be equal to: $T=854 \cdot 1,07 \approx 914$ Joule.

As a result of calculations we have received that for change the picker on slopes spends about 1000 Joule.

It is necessary to take into account that in addition, energy is still spent on making movements with hands and extension.

If the picker sits on a continuously moving platform over a row of strawberries, the energy costs will be substantially greater. To picking all the ripe berries, he leans forward in the sagittal plane at an angle of $45^{\circ}$ or more, and the legs remain on the stops under load motionless and tired. However, the picker does not always have time to picking all the ripe berries. Therefore, to reduce the tension of labor in the mass gathering on one row two operators sit opposite each other.

If the picker reclines over a row of strawberries on a continuously moving platform, he does not incline, the movement of the body gets more freedom, but the position body is such that the large muscles (dorsal) are tense almost all the time. The amplitude of the movement hands is much greater, and the hands remain largely tense. Also to rapid fatigue hands under picking berries is actually added overload of the chest and knee joints.

If the picker lies over a row of strawberries face down on a continuously or discretely moving platform, then the body movements are practically absent, and the movements hands are extremely limited. In this position, the fatigue hands, which are in the collection of berries constantly in an elevated position, will appear much faster, and the neck muscles will receive significant overload.

If the picker sits on a discretely moving platform between the rows, then due to the proximity of the bushes, the angles torso are significantly reduced (twice or more), and the feet are free on the soil or stops. This is due to the fact that the seat is much lower than in the previous case, when the collector is located above a row of strawberries. The difference in the levels of the seats is determined by the height of the bushes, the value of which, together with the height of the soil shaft row is about half the height of the body picker. However, at a lower angle of inclination picker alternately turns the body to the left or right, picking berries in the area of reach from one or the other row. These rotations can be eliminated if necessary, giving the seat the possibility rotation within $30^{\circ}$ in each direction. In fact, given the above, the position picker sitting between the rows, compared to the other three, are the best.

In addition to theoretical justification and computer simulation of the position picker, we conducted a number of laboratory experiments (Fig.2), which allowed to determine the area of coverage of the motor field with the work of one and two hands at different angles of deviation body picker, as well as it turned out that for the greatest convenience when working the seat should be able to rotate 300 in each direction (Fig. 4). 

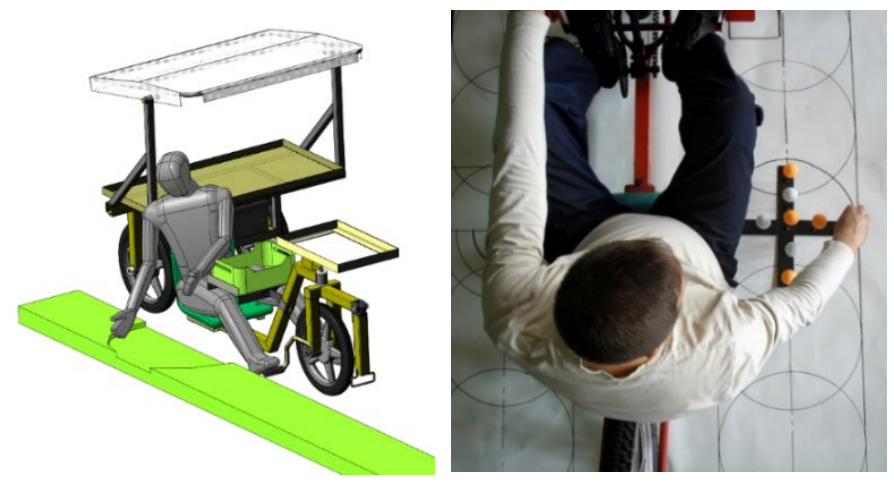

Fig. 2. Simulation of the picking process from the platform in the Compass 3D CAD system, and under laboratory conditions to study the reach zone during the assembly.

When justifying other parameters of the workplace of the picker, the height rise, the angle of rotation seat, the original technique detailed in the work was used. As a result of the studies found that the preferred location of the seat in the longitudinal direction is within 0 . $7 \ldots 0.9 \mathrm{~m}$ from the center of the seat to the footrests, seat height $0.08 \ldots 0.10 \mathrm{~m}[4,5]$.

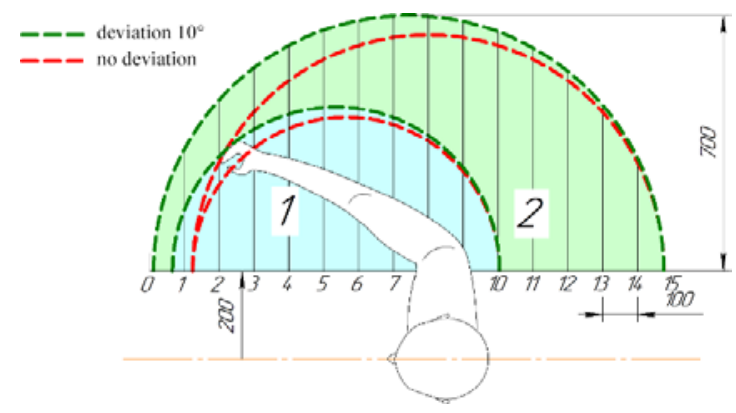

Fig. 3. Diagram of the range of the motor zone, obtained in the laboratory at different deviations : 1 harvesting area mastered by two hands, 2 - harvesting area of one hand.

Our research found that when working on the platform, the picker up to $85 \%$ of the time with two hands, mastering the area under the number 1 , and only up to $15 \%$ of the time is harvesting with one hand within the area under the number.

The area of the figure is a curved trapezoid. To simplify the calculations, divide this area into several parts, denote the areas of these figures, respectively, S1 and S2.

The lines that limit this area on the left and right are straight and represent the limits of integration. The curve is some function $\mathrm{f}(\mathrm{x})$. In this case, consider two functions $\mathrm{fl}(\mathrm{x})$ and $\mathrm{f} 2(\mathrm{x})$. The area of the curved trapezoid is determined by the formula:

$$
\mathrm{S}_{1}=\int_{\mathrm{a}}^{b} f_{1}(x)+\mathrm{S}_{2}=\int_{\mathrm{a}}^{b} f_{2}(x)
$$

The areas marked under ( number 1), the area when working with two hands:

for position without deviation $-S=0,318 \mathrm{~m}^{2}$

for deviation in $10^{\circ}-S=0,343 \mathrm{~m}^{2}$, for deviation in $30^{\circ}-S=0,373 \mathrm{~m}^{2}$

Areas of reach one hand ( number 2), without deviation $-S=0,692 \mathrm{~m}^{2}$, for deviation in $10^{\circ}-S=0,748 \mathrm{~m}^{2}$, for deviation in $30^{\circ}-S=0,8282 \mathrm{~m}^{2}$

When creating technical means for hand harvest strawberries it is necessary to take into account the size of the bushes, their structure and morphological features of certain varieties, the nature of the location of berries on the Bush, the strength properties of flower stalks, as well as the size characteristics of the aisles and rows. The analysis found that the development 
of technical means must take into account the parameters of plants within the following limits (Fig.4):

- The width of the bush of strawberries varies from 0.34 to $0.64 \mathrm{~m}$ with an average size of $0.46 \mathrm{~m}$.

- The width of the base bush is in the range of 18.5 to $0.41 \mathrm{~m}$, the average value is 0.30 $\mathrm{m}$. This value depends on the age of the plant and the quality of inter-row processing.

- The size of the bushes in height are within $0.21 \mathrm{~m}-0.45 \mathrm{~m}$ with an average value of 0.32 $\mathrm{m}$.

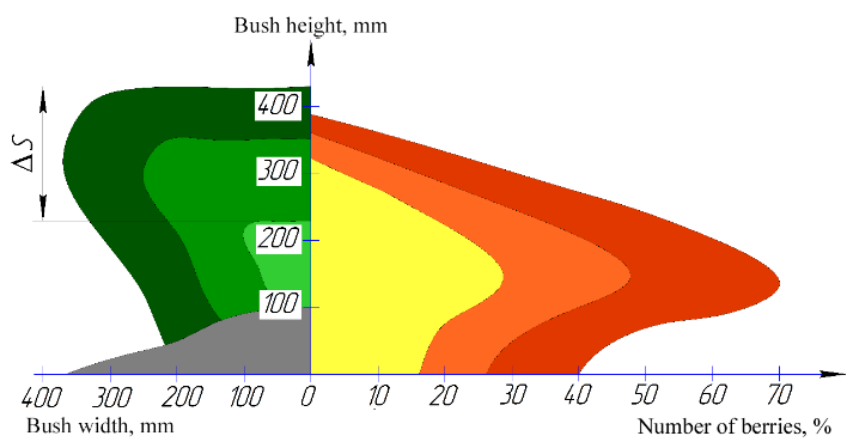

Fig. 4. Dimensional indicators of strawberry bushes.

Traditionally, the system of planting plants in a line with equal distances between plants in the rows of $0.7-1 \mathrm{~m}$ is used. the use of a two-line planting scheme is Common, with a distance between the rows of $0.60-1 \mathrm{~m}$ and a plant density of $0.15-0.20 \mathrm{~m}$. Also, cultivation in ridges is used. The width of the ridge with a one-line landing is $0.40-0.60 \mathrm{~m}$, with a twoline landing - 1-1.3 m, with four-line - $1.20-1.30 \mathrm{~m}$. (Fig.5).

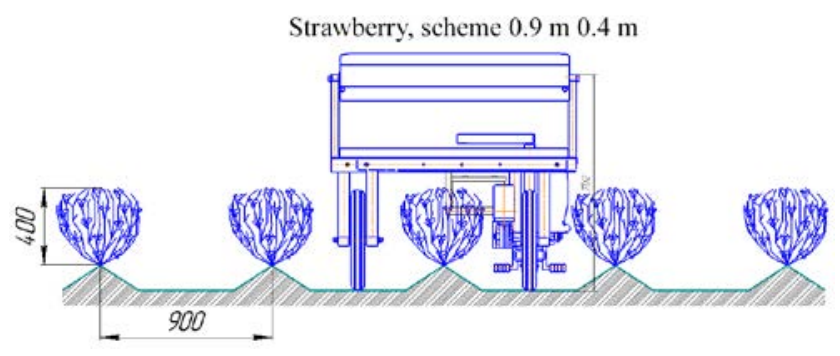

a)

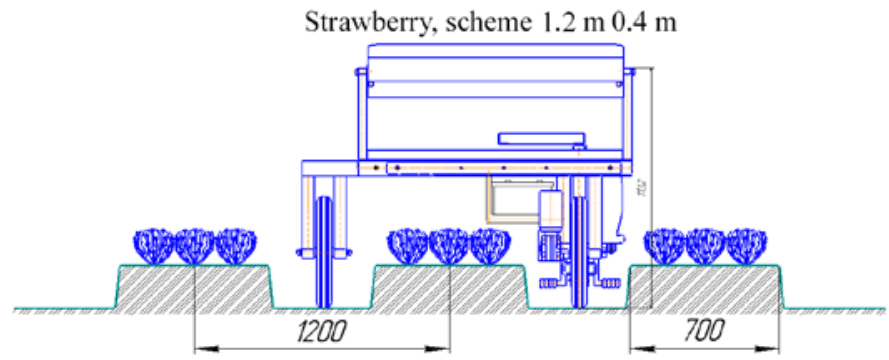

b)

Fig. 5. Constructive-technological scheme of application of the harvesting platforms: a - on the plantation of strawberries with the scheme of planting $0.9 \times 0.4$ meters, $b$ - on the plantation of strawberries with the scheme of planting $1.2 \times 0.4$ meters. 
The design chassis should be able to regulate the track platform for work on berry plantations with a width of $0.80-1 \mathrm{~m}$. This will allow the platform to be used in various technologies of cultivation of low-growing berry crops.

Structurally, the platform should consist of:

- frames made of lightweight material with one swivel seat;

- power plant with power supply system in the form of batteries;

- sun visor made of fabric awning;

- undercarriage of three aluminum alloy wheels with front steering wheel;

- remote control movement in the form of a joystick ;

- main and additional sites for packaging.

Another important feature of the development of this platform is the possibility of confident movement of the platform on wetlands with low bearing capacity, during prolonged rains and additional application of the platform on various operations on the plantation (planting, weeding, thinning). This is achieved by the optimal selection of the dimensional characteristics wheels and the necessary power and torque of the electric motor, so that the propellers do not exceed the permissible pressures on the soil.

Table 1. Standards of permissible pressures on the soil at different humidity

\begin{tabular}{|c|c|}
\hline Soil moisture & $\begin{array}{c}\text { Permissible specific pressure on soil, } \\
\mathbf{k P a}\end{array}$ \\
\hline $\mathrm{HB}$ & $40 \ldots 50$ \\
\hline $0,7-0,9$ & $80 \ldots 90$ \\
\hline $0,5-0,7$ & $100 \ldots 120$ \\
\hline $0,5 \mathrm{HB}$ & $150 \ldots 180$ \\
\hline
\end{tabular}

Calculation of the pressure of the running wheels on the soil is carried out according to the method described in GOST 26953-86 «Methods for determining the impact of propellers on the soil».

The calculation showed that the rear wheel has a pressure of $36 \mathrm{kPa}$, and the front $24 \mathrm{kPa}$. The data obtained indicate the high driving characteristics of the selected tires, which ensure the movement of the platform on soils with high moisture content and do not exceed the maximum pressure norms on the soil.

The electric motors required for the drive are selected taking into account the technical requirements for the platform, the operating speed, load capacity, the required duration of the platform without recharging. The power of the applied electric motor is calculated in several stages.

First, we calculate the rolling resistance of the wheel according to the formula:

$$
P=k^{-\frac{1}{3} 3} \sqrt{\frac{G^{4}}{B D^{2}}}
$$

where $k$ - coefficient of volumetric collapse of the soil (arable land equal to 0,76 ). Then we define the moment of resistance to rolling wheel with pneumatic tire according to the formula

$$
\mathrm{M}=P \cdot f
$$

where $f$ - coefficient of rolling friction, determined by reference, $(\mathrm{f}=0.28)$. The power required for the movement of the drive motors is determined by the formula:

$$
N=M \cdot \omega
$$

where $\omega$ - is the angular velocity of rectilinear motion, is the ratio of the working velocity of the platform to the moment of resistance of forces. 
Substituting the initial values in the formula (11), we obtain the required engine power equal to $335 \mathrm{~W}$, which, taking into account the $30 \%$ power reserve for various overloads on the drive wheels of the platform and get the desired value, for our case, a $500 \mathrm{~W}$ gear motor on the drive wheel is suitable. These calculations are recorded in table 2.

Table 2. Calculation index

\begin{tabular}{|c|c|c|c|c|c|}
\hline $\begin{array}{c}\text { Engine } \\
\text { power, W }\end{array}$ & $\begin{array}{c}\text { Wheel } \\
\text { diameter, } \mathbf{m}\end{array}$ & $\begin{array}{c}\text { Wheel } \\
\text { width, } \mathbf{m}\end{array}$ & $\begin{array}{c}\text { Torque, } \\
\mathbf{N} / \mathbf{m}\end{array}$ & $\begin{array}{c}\text { Front wheel } \\
\text { pressure, } \\
\mathbf{k P a}\end{array}$ & $\begin{array}{c}\text { Front wheel } \\
\text { pressure, } \\
\mathbf{k P a}\end{array}$ \\
\hline 500 & 550 & 0,055 & 64 & 24 & 36 \\
\hline
\end{tabular}

Since the calculated dry weight of the platform is $100 \mathrm{~kg}$, the front driven wheel does not need additional drive.

The design of the platform frame was calculated using the Autodesk Fusion 360 finite element analysis module based on the application of the finite element method (FEM). With the help of the module of physical modeling 3D kinematic model of the process adapter is visualized and a grid of finite elements (Finite Element Analysis, FEA) is created.

The finite element method is used to calculate the strength under the action of force loads, calculate the stability and the form of loss of stability, analysis of linear, angular and resultant displacements, vibrations (determination of natural and forced oscillation frequencies).

We have set certain input parameters, such as: the weight of the operator, containers and other payload, the overall dimensions of the platform based on agricultural requirements, the estimated weight of the platform.

Taking into account these data, a working version of the graphical model of the carrier frame platform was obtained. Static and dynamic loads corresponding to the specified parameters were applied in the structural units (Fig. 6), the model of the supporting frame of the platform.

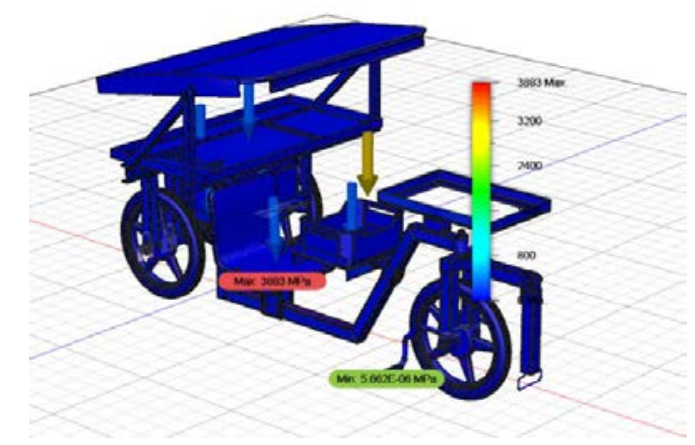

Fig. 6. Model of the supporting frame of the platform $\mathrm{c}$ to applied loads.

\section{Conclusions}

The optimal parameters of the workplace of the picker in the sitting position between the rows, providing a significant increase in the productivity of hand harvesting of strawberries: the preferred location of the seat in the longitudinal direction is within $0.7 \ldots 0.75 \mathrm{~m}$ from the center of the seat to the rack of the additional frame, the free rotation of the seat in each direction up to $30^{\circ}$, the height of the seat lift - up to $9 \mathrm{~cm}$. The area of the motor field of the collector's hands is Determined when working one from 0.692 to $0.828 \mathrm{~m}^{2}$ and two hands from 0.318 to $0.373 \mathrm{~m}^{2}$, depending on the inclination of the body. 
The track of the platform should be adjusted in the range from 1.2 to $1.8 \mathrm{~m}$, the speed should be adjusted in the range from 0.5 to $5.5 \mathrm{~km} / \mathrm{h}$, the power of the electric motor $-500 \mathrm{~W}$, torque $-64 \mathrm{~N} / \mathrm{m}$.

\section{References}

1. Kulikov I.M., Utkov Yu.A., Buchkov V.V. Technical equipment of modern industrial gardening and prospects of its improvement. Agricultural machines and technologies. № 5, pp 3-8. (2010).

2. Utkov Yu.A., Chyhlyaev I.I. The modern world trends and the development of mechanization in the cultivation of crops for intensive technologies of industrial plantations in Russia. Collection of scientific reports of the International scientific and technical conference dedicated to the 145th anniversary of academician V. P. Goryachkin. pp 230235. (2013).

3. Utkov Yu.A., Filippov R.A. Modern trends in the creation of technical means to improve working conditions in industrial horticulture in Russia. Herald of Ryazan State Agrotechnological University Named after P.A. Kostychev. № 3, pp 31-37. (2012).

4. Shkrabak V. S., Shkrabak R. V., Goldobin, V. A. Theory and practice of improvement of working conditions of operators of means of mechanization of works in rural construction. SPb.: S. PBGA,. P.238. (2001). 